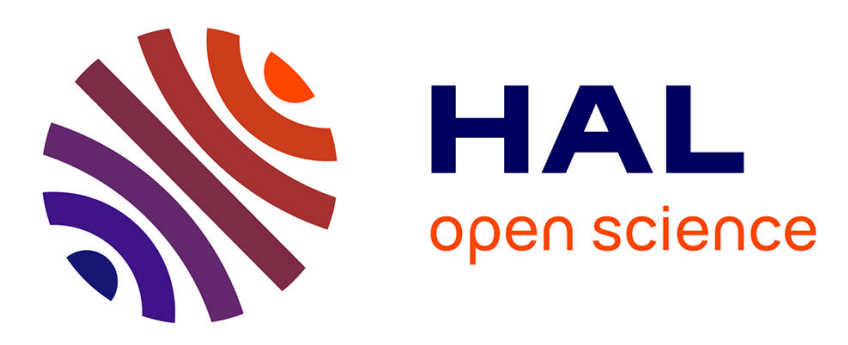

\title{
Heat Estimation from Infrared Measurement Compared to DSC for Austenite to R Phase Transformation in a NiTi Alloy
}

Vincent Delobelle, Denis Favier, Hervé Louche

\section{- To cite this version:}

Vincent Delobelle, Denis Favier, Hervé Louche. Heat Estimation from Infrared Measurement Compared to DSC for Austenite to R Phase Transformation in a NiTi Alloy. Journal of Materials Engineering and Performance, 2013, 22 (6), pp.1688-1693. 10.1007/s11665-012-0466-y . hal-01300481

\section{HAL Id: hal-01300481 \\ https://hal.science/hal-01300481}

Submitted on 11 Apr 2016

HAL is a multi-disciplinary open access archive for the deposit and dissemination of scientific research documents, whether they are published or not. The documents may come from teaching and research institutions in France or abroad, or from public or private research centers.
L'archive ouverte pluridisciplinaire HAL, est destinée au dépôt et à la diffusion de documents scientifiques de niveau recherche, publiés ou non, émanant des établissements d'enseignement et de recherche français ou étrangers, des laboratoires publics ou privés. 


\title{
Heat estimation from infrared measurement compared to DSC for Austenite to $\mathbf{R}$ phase transformation in a NiTi alloy.
}

\author{
V. Delobelle ${ }^{(1)}$, D. Favier ${ }^{(1)}$ and H. Louche ${ }^{(2)}$ \\ (1) Université de Grenoble/CNRS, Laboratoire 3SR, BP 53, 38041 Grenoble Cedex 9.
} Tel : 0476827042

Denis.Favier@grenoble-inp.fr

(2) Laboratoire de Mécanique et de Génie Civil (LMGC), Université Montpellier 2, CNRS, cc 048, Place Eugène Bataillon, 34095 Montpellier Cedex

Tel : 0467149634

herve.louche@univ-montp2.fr

\begin{abstract}
:
Heat sources estimations from temperature field measurements deduced from infrared imaging are increasingly used to study thermo-mechanical coupling during materials deformation. These estimations are based on approximations of the derivative terms with respect to time and space which are involved in the heat diffusion equation. This paper proposes a first experimental validation of this method by applying it to an experimental uniform air cooling of a NiTi Shape Memory Alloy thin plate. In the studied cooling temperate range, heat sources are due to Austenite to R phase transformation. Transformation temperatures, heat sources and energies are estimated from infrared temperature measurements and compared to differential scanning calorimetry results. The small
\end{abstract}


discrepancies are mainly explained by errors in DSC measurements due to thermal inertia and baseline determination.

Key Word: Heat source estimation, infrared thermal field measurement, DSC, NiTi, A-R transformation.

\section{Introduction}

Infrared temperature field measurements are increasingly used to analyze the thermal manifestations accompanying materials deformation. Intensity and spatio-temporal temperature variations depend on the deformation mechanisms (elasticity, plasticity, viscosity, damage, phase transformation, etc.) but also on the thermal problem characteristics (geometry, thermal properties, boundary conditions, etc.). Heat sources determination from infrared temperature measurement has been shown to be helpful to analyze deformation mechanisms of various materials (Ref $1,2,3,4)$. A first class of methods of heat sources estimation is based on inverse methods (Ref 5, for example). The method used in the present study was presented in (Ref 1). It is based on (i) temperature field measurements at the surface of a thin sample and then on (ii) approximations of temperature first derivative with respect to time and second derivative with respect to space involved in the local heat diffusion equation.

Heat sources estimations were validated on test cases with synthetic data produced by solving direct problems with known heat sources using analytical or numerical models (Ref 1,6$)$. Finite element simulations generate temperature fields, which are corrupted with a random noise. Performances of the heat sources estimation methods were evaluated from these synthetic data. 
The aim of this paper is to validate experimentally in a simple case the heat source estimation method proposed in (Ref 1). Uniform air cooling experiments were performed on a NickelTitanium (NiTi) shape memory alloy (SMA) exhibiting two transformation steps during cooling from austenitic phase (A) to $R$ phase $(\mathrm{R})$ and then to martensitic phase (M).This material was chosen because its transformation behavior is stable with thermal cycling. Heat sources were estimated from infrared measurements in the temperature range of the A-R transition. Transformation temperature, heat sources and energy obtained with this method were finally compared to values obtained from usual differential scanning calorimetry (DSC) measurements.

Firstly, material, experimental set-up and method to achieve such a validation are exposed. Then, results are presented and discussed.

\section{Material and method}

\subsection{Used thermal model.}

Let us consider an air cooled sample with initial uniform temperature $T_{0}$. The local heat diffusion equation governing the cooling of the sample reads:

$$
C \frac{\partial T}{\partial t}-k \operatorname{lap}(T)=\dot{q}(t)
$$

where $T$ is the current local temperature depending on the spatial position and time $t, C$ the heat capacity, $k$ the isotropic thermal conductivity and $\dot{q}$ the specific internal heat sources.

Three thermal models have been proposed by Chrysochoos and Louche (Ref 1) which were obtained by simplifying the previous equation successively in the case of thin plates of thickness $e$ with uniform temperature and heat source throughout the plate thickness (2D 
model), then in the case of slender thin samples with temperature and heat source considered as depending only on the axial position and time (1D model) and lastly in the case of small thin samples with temperature and heat sources considered as uniform throughout the sample and depending only on time (0D model). In this paper, we use this $0 \mathrm{D}$ thermal model which reads:

$$
C \frac{\partial \theta(t)}{\partial t}=\dot{q}(t)-\frac{f}{\rho e}
$$

where $\theta=T-T_{0}$ is the temperature variation and $\rho$ the density. The function $f$ models heat losses from the lateral surfaces of the thin sample per unit of area. In this study, heat losses by free convection and radiant emission are considered, leading to the following expression of $f$ :

$$
f=f_{\text {conv }}+f_{\text {rad }}=2 h\left(T-T_{a}\right)+2 \varepsilon \sigma\left(T^{4}-T_{a}^{4}\right),
$$

where $h$ is the convection coefficient, $\varepsilon$ the emissivity of the sample surfaces, $\sigma$ the StefanBoltzman constant, and $T_{a}$ the ambient temperature. The heat loss by convection is due to transfer of heat energy between the sample surface and moving surrounding fluid; in the equation Eq.3, $h$ is dependent on a lot of factors, including sample and surrounding fluid temperatures. Possible heat losses from the insulating wires are assumed negligible compared to convection and radiation heat losses and were neglected in the heat loss function.

\subsection{Material}

The air cooling experiments were performed on a commercial NiTi alloy bright rolled plate of thickness $e=0.39 \mathrm{~mm}$ with a nominal composition Ti-50.2 at.\%Ni. The transformation behaviour of this alloy was characterized using TA Q200 differential scanning calorimeter 
with a heating and cooling rate of $10 \mathrm{~K} \mathrm{~min}^{-1}$, for a temperature range between $-90^{\circ} \mathrm{C}$ and $+120^{\circ} \mathrm{C}$. The DSC was performed on a sample of $22.9 \mathrm{mg}$ cut with diamond blade.

As shown in Fig.1, at cooling, the transformation is composed of two stages: austenite (A) to R-phase (R) and then R-phase to martensite (M). During heating, a single-step M-A is observed. From this DSC thermogram, the characteristic temperatures during heating, the austenite start temperature $A_{s}=69^{\circ} \mathrm{C}$ and the austenite finish temperature $A_{f}=84^{\circ} \mathrm{C}$, and those during cooling, the $\mathrm{R}$ phase start temperature $R_{s}=62^{\circ} \mathrm{C}$, the $\mathrm{R}$ phase finish temperature $R_{f}=53^{\circ} \mathrm{C}$, the martensite start temperature $M_{s}=39^{\circ} \mathrm{C}$ and the martensite finish temperature $M_{f}=12^{\circ} \mathrm{C}$ were determined in a standard way described for example in (Ref 7). From this curve, at temperature higher than $95^{\circ} \mathrm{C}$, the material is fully austenitic.

\subsection{Experimental validation method}

Experimental validation of the heat source estimation was performed during air cooling experiments of two samples, a reference one (1) and a NiTi sample (2), as shown in Fig. 2. In that study, the reference sample is a pure Titanium plate of thickness $e=0.50 \mathrm{~mm}$, width $5 \mathrm{~mm}$ and length $15 \mathrm{~mm}$. The dimensions of the NiTi plate are identical except a little smaller thickness $e=0.39 \mathrm{~mm}$,

Firstly, the two samples were coated with a high emissivity paint $(\varepsilon=0.95)$, in order to have identical emissivity. Then, they were put in a first climatic chamber (chamber n.1) during approximately 45 minutes at a temperature $T_{l}=100^{\circ} \mathrm{C}$. As shown in Fig.1, at this temperature the NiTi plate was fully austenitic. Then, the two samples were transported from the chamber n.1 to a second climatic chamber (chamber n.2) maintained at temperature $T_{2}=0^{\circ} \mathrm{C}$. A specific device has been designed to reduce cooling during the carrying of the two samples between the two chambers. During all the experiment, the two samples were suspended with insulating 
wires to obtain uniform temperature. The samples temperatures were measured during air cooling in the chamber n.2 by means of an infrared camera, placed outside the chamber. This observation was done through a transparent infrared window with a transmission coefficient $\tau=0.92$. Due to frost problem, the temperature of the chamber 2 could not be lower than $0^{\circ} \mathrm{C}$. Note that, with appropriate chamber temperatures $T_{1}$ and $T_{2}$, it would also be possible to use the experimental set-up during heating.

During the air cooling experiment, the temperature $\mathrm{T}_{\mathrm{NiTi}}$ is measured for the NiTi sample, leading to the temperature variation estimation $\theta_{\mathrm{NiTi}}=\mathrm{T}_{\mathrm{NiTi}}-\mathrm{T}_{2}$. The $0 \mathrm{D}$ thermal model (see Eq.2) allows estimating heat sources $\dot{q}$ involved during cooling of this sample if the heat loss function $f$ is known. In order to estimate $f$, measurement of the temperature during simultaneous cooling of the reference sample is used, as described in the following. Due to the paint, emissivities of the two samples were identical and thus the heat loss due to radiant emission $f_{\text {rad }}$ is only dependent on sample temperature, i.e. $f_{\text {rad }}(T)$. The heat loss due to convection $f_{\text {conv }}$ is always difficult to estimate ( $\operatorname{Ref} 8$ ). In order to determine it, the two samples in the chamber n. 2 at temperature $T_{2}=T_{a}$ were considered being submitted, at a given sample temperature $T$, to identical thermal surface conditions and no assumption is done with the dependence of $h$ on $T$. Convection heat $\operatorname{loss} f_{\text {conv }}$ is then also taken as only dependent on sample temperature $f_{\text {conv }}(T)$. With these two assumptions, in the conditions of our air cooling experiments, the heat loss function $f$ was only dependent on the sample temperature $f(T)$ and independent of the sample material, i.e. identical for the reference and NiTi samples. This allows determining $f(T)$ from temperature measurements of the reference Titanium sample ; during cooling, there was no internal heat sources in this sample and thus $f(T)$ was determined from the cooling curve of the Titanium sample by estimating the left hand side of equ.2, with the material properties of the Titanium sample listed in Table 1. This function $f(T)$ is then 
used to estimate heat sources $\dot{q}$ for the NiTi sample using equation (2) and material properties of the NiTi sample listed in Table 1. For that study, heat capacity of the Titanium and NiTi samples were measured with classical DSC, which is the common instrument to measure heat capacity. Thus, it comes:

$$
\dot{q}_{N i T i}=C_{N i T i} \frac{\partial \theta_{N i T i}(t)}{\partial t}-\frac{\rho_{T i} e_{T i}}{\rho_{N i T i} e_{N i T i}} C_{T i} \frac{\partial \theta_{T i}(t)}{\partial t} .
$$

Fig.3 summarizes the flowchart of the different steps proposed to validate the method. In the following, results obtained by calorimetry on one hand and those obtained from the infrared measurements on the other hand will be distinguished by DSC (Differential Scanning Calorimetry) and TFM (Thermal field measurement), respectively. It's not possible to compare directly heat sources $\dot{q}$ measured by infrared imaging, $\dot{q}_{T F M}$ with those measured by DSC, $\dot{q}_{D S C}$, since the DSC measurement was performed at constant cooling rate $\dot{T}_{D S C}=10 \mathrm{~K} \mathrm{~min}{ }^{-1}$ while the temperature rate $\dot{T}_{T F M}$ during air cooling was obviously not constant. In both cases, we have converted the heat sources $\dot{q}$ to $\left(\frac{\dot{q}}{\dot{T}}\right)$ since for a thermal martensitic transformation, the specific heat power is proportional to the heating/cooling rate of the sample. The experimental validation of the heat sources estimation is finally performed by comparing the evolutions of the two ratios $\left(\frac{\dot{q}}{\dot{T}}\right)_{T F M}$ and $\left(\frac{\dot{q}}{\dot{T}}\right)_{D S C}$, as function of temperature.

\section{Results and discussion}

Fig.4.a shows the infrared temperature measurement during simultaneous air cooling of the Titanium and NiTi samples. The cooling kinetics were very different for the two samples. The Titanium specimen cooled with temperature decreasing approximately exponentially with time, with its final temperature equal to $0^{\circ} \mathrm{C}$, the ambient temperature of the chamber $\mathrm{n} .2$. 
Two bumps were observed in the NiTi cooling curve. They are due to the two A-R and R-M exothermic transformations involved in the studied cooling temperature range.

Fig.4.b shows the cooling rates $\dot{T}_{T F M}$ of the two samples during air cooling. They are between one and almost two magnitude orders higher than the constant cooling rate $\dot{T}_{D S C}=0.17 \mathrm{~K} \mathrm{~s}^{-1}$ of the DSC, plotted in dashed line. The Titanium cooling rate is appreciably linearly decreasing with the temperature, which is explained by the fact that the heat losses were mainly due to the convection term in eq (3) and that the coefficient convection $h$ was approximately constant during the experiment. The two peaks observed in the cooling rate curve for the NiTi sample reveal clearly the occurrence of the two phase transformations during the studied temperature range.

From now on, the analysis will be restricted to the temperature range $90-39^{\circ} \mathrm{C}$ involving only the A-R transformation. First, this transformation is less affected by thermal cycling compared to A-M or R-M transformation, both for transformation temperatures and heats (Ref 11). Moreover, Kustov et al (Ref 12) proved recently that this A-R transformation is purely athermal. Two successive air cooling experiments were performed using the same Titanium and NiTi plates. The ratio $\left(\frac{\dot{q}}{\dot{T}}\right)_{T F M}$ is then plotted as function of the temperature in Fig. 5 for the first and second coolings. The two curves are very close, which demonstrates the repetitiveness of the heat sources estimations using the developed cooling experiment.

Fig. 6.a. shows the $\left(\frac{\dot{q}}{\dot{T}}\right)$ ratios as function of temperature deduced from DSC measurements (gray DSC curve) and from air cooling experiments with infrared temperature measurement (black TFM curve). During a DSC measurement, the measured specific heat power includes 
the specific sensible heat power associated with the heat capacity of the material and the imbalance of sensible heat power between the material and reference pans. In that study the heat power difference between pans is negligible compare to the power obtained from the sample. In order to calculate the specific latent heat power for a SMA (Ref 7), a baseline is drawn joining the respective initiation and ending of the transformation. Three baselines have been tentatively sketched in the DSC curve of Fig.6 a. Classically the transformation temperature can be estimated according to tangent lines built on the peaks, as it was done in Fig1. However, depending on the choice of the two points used to build these baselines, these transformation temperatures, and even more the associated latent heat, can be different. Here, it is proposed to estimate the "transformation initiation temperature" of $\mathrm{R}$ phase (noted $\mathrm{R}_{\mathrm{si}}$ ) from the TFM curve in Fig6a. This temperature corresponds to the beginning of the increase of the TFM curve during cooling, and was estimated to $\mathrm{R}_{\mathrm{si}}=74^{\circ} \mathrm{C}$. The end of the transformation is also difficult to estimate from the DSC. Thus, the same approach, based on the TFM curve, was proposed to estimate the transformation ending temperature (noted $\mathrm{R}_{\mathrm{se}}$ ): $46^{\circ} \mathrm{C}$. The first baseline (noted 1 in Fig6a) was then built with the two transformation temperature values $\left(46^{\circ} \mathrm{C}\right.$ and $\left.74^{\circ} \mathrm{C}\right)$. From the DSC curve, the heat flow stops to decrease at $40^{\circ} \mathrm{C}$. This value was used to sketch the second baseline (notes 2 in Fig6a). The third baseline is the one commonly used for this kind of transformation, joining the initiation and the ending of the full transformation, in which the ending transformation was $5^{\circ} \mathrm{C}$, as sketched in Fig. 1 .

Specific heat energies $E$ are plotted as function of cooling temperature in Fig.6.b for the two techniques, by integrating the ratio $\left(\frac{\dot{q}}{\dot{T}}\right)$ plotted in Fig.6.a, over the transformation temperature range. For the TFM curve, the heat source plotted in Fig.6.a is only due to the A-R transformation, thus $E(T)$ is obtained by simple integration of the ratio $\left(\frac{\dot{q}}{\dot{T}}\right)$ between the transformation initiation temperature, taken equal to $R_{s i}=74^{\circ} \mathrm{C}$ and the current temperature 
T. For the DSC curve of Fig.6.a, the specific sensible heat power is approximated by the baseline and has to be deduced from the heat sources measured by DSC before integration between the transformation-initation temperature and the current temperature. Three curves of $E(T)$ determined by DSC are plotted in Fig.6.b associated with the three baselines sketched in Fig.6.a.

Figs.6.a and 6.b allow assessing heat sources estimation based on infrared measurement, by comparing determined transformation temperatures, heat sources and energies from the TFM curves with those from DSC curves. Transformation temperatures are observed in Fig.6.a. The initiation and ending transformation temperatures are difficult to estimate for the two techniques; they are even more difficult to evaluate from the DSC curve because determination of a baseline is required. The characteristic A-R transformation temperatures deduced from the TFM and DSC curves of Fig.6.a are $R_{S}^{T F M}=64^{\circ} \mathrm{C}$ and $R_{f}^{T F M}=53^{\circ} \mathrm{C}$, almost equal to the DSC values $R_{S}=63^{\circ} \mathrm{C}$ and $R_{f}=57^{\circ} \mathrm{C}$. Several papers (Ref 11) define the characteristic transformation temperature $T_{A-R}$ as measured at the maximum heat flow. The values of $T_{A-R}$, as determined using TFM and DSC methods, are indicated in Fig.6.a, being equal to $T_{A-R}^{T F M}=60^{\circ} \mathrm{C}$ and $T_{A-R}=58^{\circ} \mathrm{C}$ respectively. The differences between each of the three characteristic transformation temperatures as determined from TFM and DSC curves are smaller than $2{ }^{\circ} \mathrm{C}$; it is in the accuracy range on absolute temperatures measured by an infrared camera, equal to $\pm 2^{\circ} \mathrm{C}$. Moreover, the error on temperature variations (thermal resolution) measured by infrared camera is of the order of $\pm 0.02^{\circ} \mathrm{C}$. This is consistent with the fact that the three characteristic transformation temperatures are always higher of 1 to $2{ }^{\circ} \mathrm{C}$ for the TFM curve compared to the DSC curve. It is worth recalling that these transformation temperatures were obtained for the TFM curves for a cooling rate of approximately $4 \mathrm{~K} \mathrm{~s}^{-1}$ compared to 
$0.17 \mathrm{~K} \mathrm{~s}^{-1}$ for the TFM curve. The TFM method allows estimating accurately transformation temperatures even for fast temperature rate.

Fig.6.b allows comparing heat energy estimation. For estimation based on the DSC curve, it appears clearly that the choice of the baseline influences consequently the obtained value for the heat energy (Ref 7). The deduced values for the A-R latent heat are respectively $5.2 \mathrm{~J} \mathrm{~g}^{-1}$ and $6.2 \mathrm{~J} \mathrm{~g}^{-1}$ for the first and second baselines, respectively. From the TFM curve in Fig.6.b, the value of the heat energy at the end of the A-R transformation is $6.0 \pm 0.2 \mathrm{~J} \mathrm{~g}^{-1}$. This value is between the two DSC values obtained with the two. The third baseline used for the DSC technique does not allow an accurate determination of the A-R latent heat of transformation as the two first baselines did. Finally, it can be noted that the TFM curve $E(T)$ reveals interestingly that R-M transformation initiated approximately at $42^{\circ} \mathrm{C}$.

In Fig 6.b, in the middle of the A-R transformation, the heat energy increases faster for the TFM curve than for the three DSC curves. This is likely explained by thermal inertia effect of the DSC technique, as studied in (Ref 13, 14). This effect doesn't exist in the TFM method, even if at the beginning of the transformation, the temperature cooling rate for the TFM curve is approximately $7 \mathrm{~K} \mathrm{~s}^{-1}, 40$ times faster than the temperature rate used in the DSC experiments.

A last remark concerns the strong hypothesis of a constant heat capacity $C$ in the current TFM method. For NiTi SMAs, heat capacity is weakly temperature dependent and values reported in the literature are different for austenite and martensite (Ref 15,16$)$, although very scattered. Values for the R phase are scarce. The constant heat capacity hypothesis in the TFM model could explain the non zero value for the heat flow in Fig.6.c for temperature higher than $76^{\circ} \mathrm{C}$. 
It could also explain the weak heat source for temperature around $45^{\circ} \mathrm{C}$, another explanation being some finishing $\mathrm{A}-\mathrm{R}$ transformation and initiating $\mathrm{R}-\mathrm{M}$ transformation in this temperature range. From a theoretical point of view, the method to remove this hypothesis in the TFM method can be based on the same approach as the one proposed for the possible variation of the thermal conductivity in (Ref 17).

\section{Conclusion}

This paper presents a first experimental validation of heat source and energy estimations obtained from infrared measurements. This validation was performed during uniform cooling of a NiTi SMA in the temperature range of the Austenite-to-R phase transformation. The validation was based on comparison of the determined heat sources normalized by the temperature rate and energy as function of temperature with reference measurements obtained with classical DSC technique. A qualitative and quantitative agreement was obtained between these two techniques. The comparison emphasizes the errors of the DSC technique due to thermal inertia phenomena which are reduced in our method, since it is a technique without contact. Validations of the 1D (slender thin samples) and 2D (thin plate sample or tube) heat source estimations with an identical technique, but with adapted experimental set-ups, are in progress. This will allow applying with confidence this heat source estimation method during mechanical testing, in particular during superelastic deformation of NiTi SMA.

\section{Acknowledgement}

This work is partially supported by the French National Research Agency Program N.2010 BLAN 90201. 


\section{References}

1. A. Chrysochoos and H. Louche, An infrared image processing to analyse the calorific effects accompanying strain localization, Int J Eng Sci, 38(16), 2000, p1759-1788.

2. H. Louche, P. Vacher, R. Arrieux, Thermal observations associated with the Portevin-Le Chatelier effect in an al-mg alloy, Mater. Sci. Eng. A, 404, 2005, p 188-196.

3. D. Favier, H. Louche, P. Schlosser, L. Orgéas, P. Vacher and L Debove, Homogeneous and heterogeneous deformation mechanisms in an austenitic polycrystalline Ti-50.8 at.\% Ni thin tube under tension. Investigation via temperature and strain fields measurements, Acta Mater, 55(16), 2007, p 5310-5322.

4. S. Dumoulin, H. Louche, O.S. Hopperstad and T. Borvik, Heat sources, energy storage and dissipation in high strength steels: Experiments and modelling, Europ. J. of Mech. ASolids, 29, 2010, p 461-474.

5. N. Renault, S. Andre, D. Maillet and C. Cunat. A two-step regularized inverse solution for 2-D heat source reconstruction, Int. J. of Thermal Sc., 47, 2008, p 834-847.

6. P. Schlosser, H. Louche, D. Favier, and L. Orgéas, Image processing to estimate the heat sources related to phase transformations during tensile tests of NiTi tubes, Strain, 43(3), 2007, p 260-271. 
7. J.A. Shaw, C.B. Churchill and M.A. Iadicola, Tips and tricks for characterizing shape memory alloy wire: Part 1- Differential scanning calorimetry and basic phenomena, Experimental Techniques, 2008, p 55-62.

8. C. Zanotti, P. Giuliani, S. Arnaboldi and A. Tuissi, Analysis of Wire Position and Operating Conditions on Functioning of NiTi Wires for Shape Memory Actuators, Journal of Materials Engineering and Performance, 20 (4-5), 2011, p 688-696

9. Cambridge UK 2010 Granta design Ltd, 20 Trumpington Street. Ces selector software.

10. Y. Terada, K. Ohkubo, K. Nakagawa, T. Mohri and T. Suzuki T. Thermal conductivity of B2-type aluminides and titanides, Intermetallics, 3, 1994, p 347-355.

11. D. Favier and Y. Liu, Restoration by rapid overheating of thermally stabilised martensite of NiTi shape memory alloys, J. of Alloys and Compounds, 297, 2000, p 114-121.

12. S. Kustov, D. Salas, E. Cesari, R. Santamarta, J. Van Humbeeck, Isothermal and athermal martensitic transformations in NiTi shape memory alloys », Acta Materialia (2012) , in press, doi:10.1016/J;actamat.2012.01.025

13. Q. Meng, H. Yang, Y. Liu, T.H. Nam and F. Chen, Thermal arrest analysis of thermoelastic martensitic transformations in shape memory alloys, J. of Mater. Research, 26(10), 2011, p 1243-1252. 
14. H. Kato, K. Sasaki, Avoiding error of determining the martensite finish temperature temperature due to thermal inertia in differential scanning calorimetry: model and experiment of NiTi and Cu-Al-Ni shape memory alloys, J. Mater Sci, 47, 2012, p 13991400.

15. M. Faulkner, J. Amalraj, A. Bhattacharyya Experimental determination of thermal and electrical properties of Ni-Ti shape memory wires. Smart Mater Struct, 9, 2000, p622-631

16. P.Bassani, P.Giuliani, A. Tuissi and C.Zanotti, Thermomechanical properties of Porous NiTi Alloy produced by SHS, Journal of Materials Engineering and Performance, 18 (5-6), 2009, p 594-599

17. H. Louche, P. Schlosser, D. Favier, L. Orgéas, Heat source processing for localized deformation with non-constant thermal conductivity- Application to superelastic tensile tests of NiTi Shape Memory alloys, accepted for publication in Experimental Mechanics, 2012.

\section{Table}

\begin{tabular}{|c|c|c|c|}
\hline & $\begin{array}{c}\text { Thickness } \\
\text { (mm) }\end{array}$ & $\begin{array}{c}\text { Density } \\
\rho\left(\mathrm{kg} \mathrm{m}^{-3}\right)\end{array}$ & $\begin{array}{l}\text { Heat capacity } \\
C\left(\mathrm{~J} \mathrm{~kg}^{-1} \mathrm{~K}^{-1}\right)\end{array}$ \\
\hline Pure Titanium sample (Ref 9) & 0.510 & 4510 & 520 \\
\hline NiTi (Austenite) sample (Ref 10) & 0.386 & 6500 & 520 \\
\hline
\end{tabular}

Table 1: Titanium and NiTi samples properties 


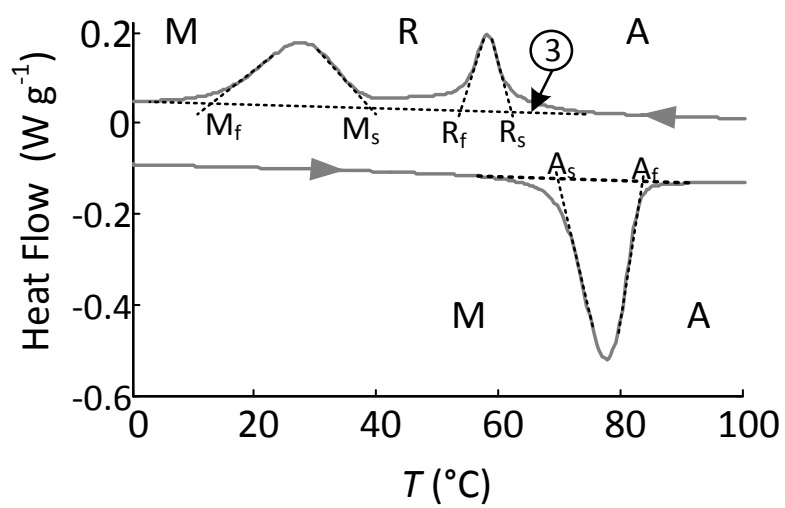

Fig.1: Differential scanning calorimetry thermogram of the NiTi sample.

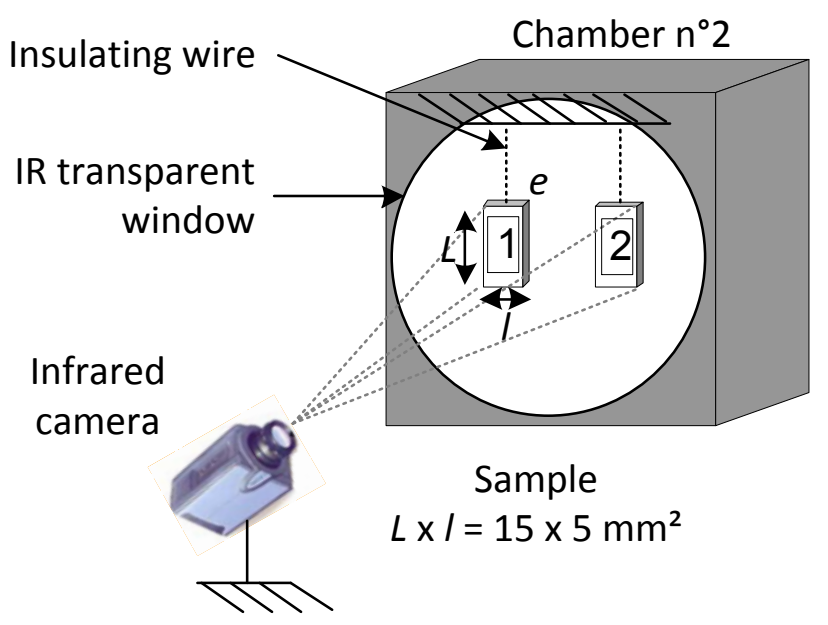

Fig.2 : Experimental set-up.

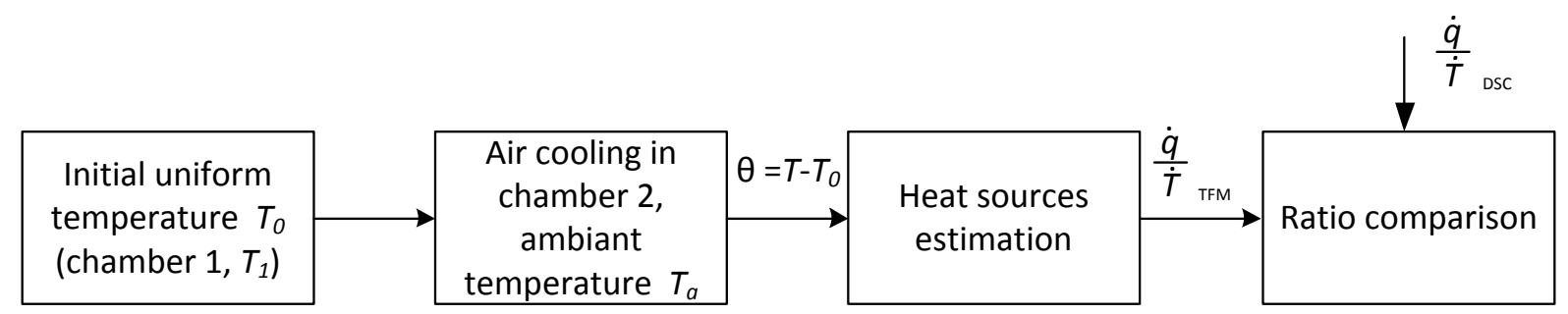

Fig.3 : Flowchart of the experimental validation of the heat sources estimation. 

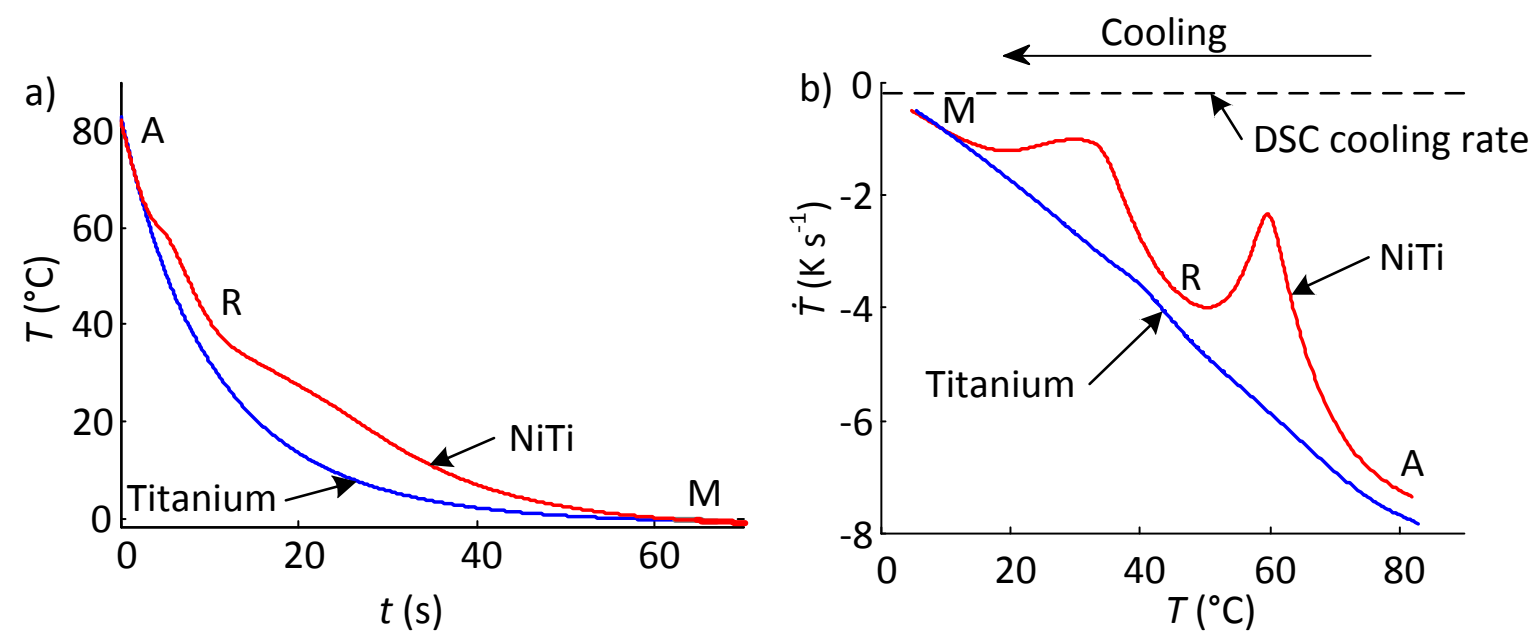

Fig. 4 : a) Cooling curves of Ti and NiTi samples. b) Cooling rate curves.

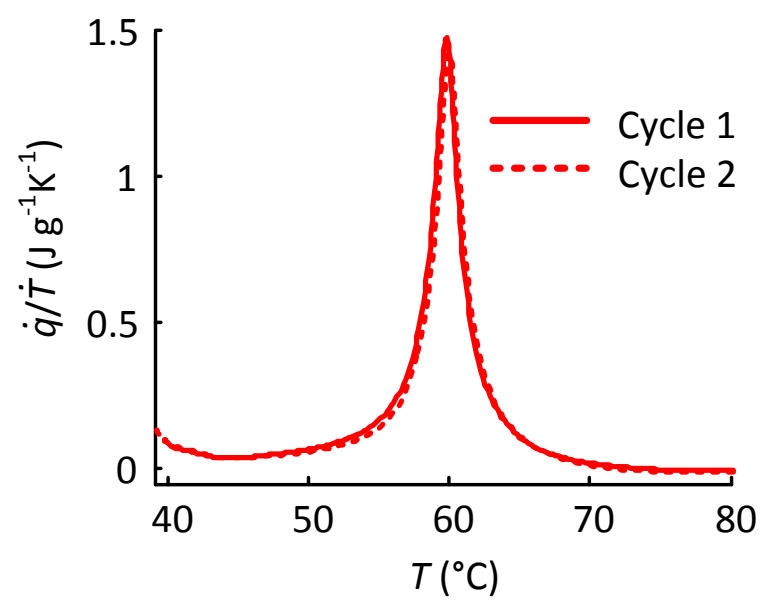

Fig. 5 : Heat flow normalized by the temperature rate $\left(\frac{\dot{q}}{\dot{q}}\right)$ for two successive cooling experiments performed with the same sample. 

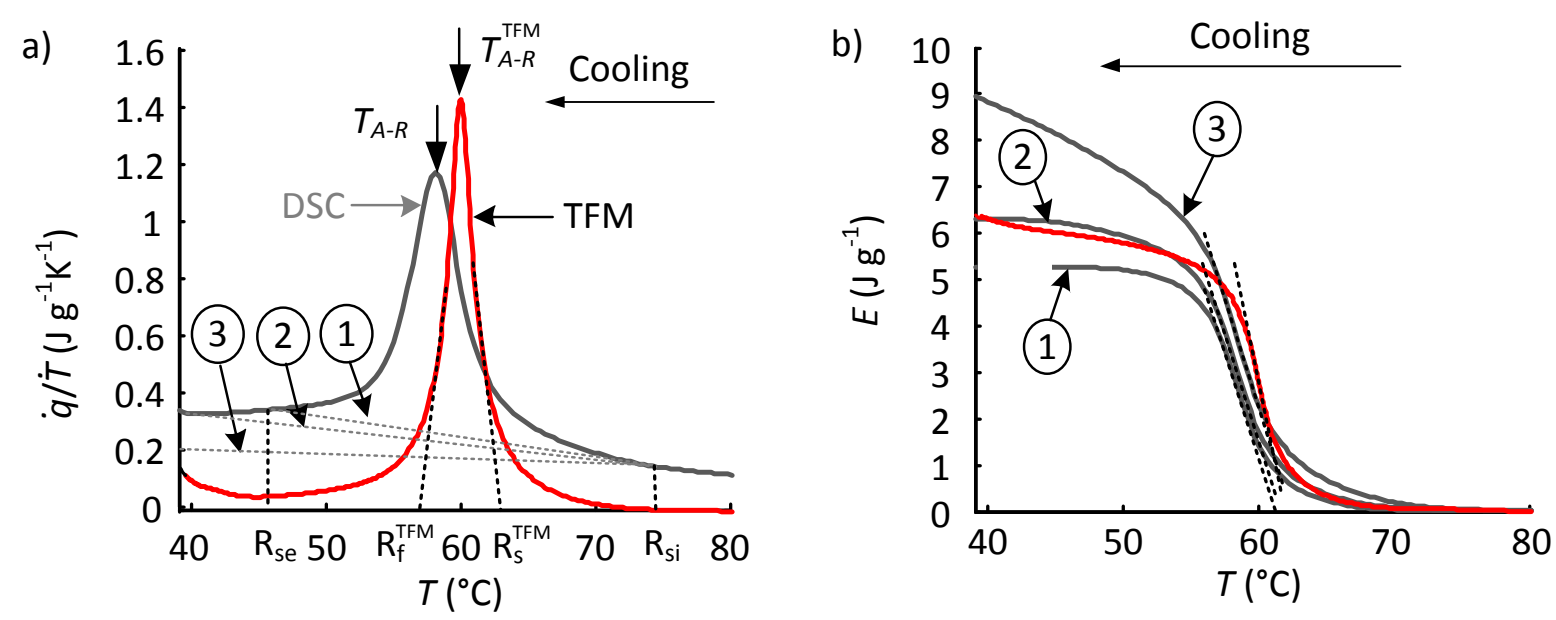

Fig.6 : a) : Heat flow normalized by the temperature rate $\left(\frac{\dot{q}}{\dot{T}}\right)$ for DSC and air cooling experiments. b) : Energy estimations obtained with these two techniques 